\title{
BMJ Open Sources of social support associated with health and quality of life: a cross-sectional study among Canadian and Latin American older adults
}

\author{
Emmanuelle Bélanger, ${ }^{1}$ Tamer Ahmed, ${ }^{2}$ Afshin Vafaei, ${ }^{3}$ Carmen Lucia Curcio, ${ }^{4}$ \\ Susan P Phillips, ${ }^{5}$ Maria Victoria Zunzunegui ${ }^{6}$
}

To cite: Bélanger $E$ Ahmed T, Vafaei A, et al. Sources of social support associated with health and quality of life:

a cross-sectional study among Canadian and Latin American older adults. BMJ Open 2016;6:e011503. doi:10.1136/bmjopen-2016011503

- Prepublication history for this paper is available online To view these files please visit the journal online (http://dx.doi.org/10.1136/ bmjopen-2016-011503).

Received 16 February 2016 Revised 1 June 2016 Accepted 6 June 2016

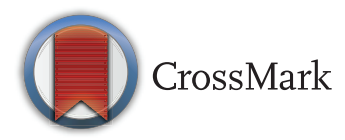

For numbered affiliations see end of article.

Correspondence to Dr Emmanuelle Bélanger; e.belanger@umontreal.ca

\section{ABSTRACT}

Objectives: To examine whether the association between emotional support and indicators of health and quality of life differs between Canadian and Latin American older adults.

Design: Cross-sectional analysis of the International Mobility in Aging Study (IMIAS). Social support from friends, family members, children and partner was measured with a previously validated social network and support scale (IMIAS-SNSS). Low social support was defined as ranking in the lowest site-specific quartile. Prevalence ratios (PR) of good health, depression and good quality of life were estimated with Poisson regression models, adjusting for age, gender, education, income and disability in activities of daily living.

Setting: Kingston and Saint-Hyacinthe in Canada, Manizales in Colombia and Natal in Brazil.

Participants: 1600 community-dwelling adults aged $65-74$ years, $n=400$ at each site.

Outcome measures: Likert scale question on self-rated health, Center for Epidemiological Studies Depression Scale and 10-point analogical quality-of-life (QoL) scale.

Results: Relationships between social support and study outcomes differed between Canadian and Latin American older adults. Among Canadians, those without a partner had a lower prevalence of good health ( $\mathrm{PR}=0.90 ; 95 \% \mathrm{Cl} 0.82$ to 0.98 ), and those with high support from friends had a higher prevalence of good health ( $P R=1.09 ; 95 \% \mathrm{Cl} 1.01$ to 1.18). Among Latin Americans, depression was lower among those with high levels of support from family ( $P R=0.63$; $95 \% \mathrm{Cl} 0.48$ to 0.83 ), children ( $\mathrm{PR}=0.60 ; 95 \% \mathrm{Cl} 0.45$ to 0.80 ) and partner ( $\mathrm{PR}=0.57 ; 95 \% \mathrm{Cl} 0.31$ to 0.77 ); good QoL was associated with high levels of support from children ( $P R=1.54 ; 95 \% \mathrm{Cl} 1.20$ to 1.99 ) and partner ( $\mathrm{PR}=1.31 ; 95 \% \mathrm{Cl} 1.03$ to 1.67 ).

Conclusions: Among older adults, different sources of support were relevant to health across societies. Support from friends and having a partner were related to good health in Canada, whereas in Latin America, support from family, children and partner were associated with less depression and better QoL.

\section{Strengths and limitations of this study}

- This study examines the associations between emotional support and self-rated health (SRH), depression and quality of life in cross-cultural samples of older adults.

- The measure of emotional support (International Mobility in Aging Study-social network and support scale) has been validated in the study population and differentiates between different types of social ties.

- The study protocol and measurement instruments were identical across international sites, allowing rigorous cross-cultural comparison.

- While cross-sectional data cannot ascertain the direction of the associations between social support and health outcomes, the associations between SRH, depression and quality of life with social support from different sources are significant and strong and they vary across cultures.

\section{INTRODUCTION}

Population ageing is a global phenomenon, affecting developed and developing countries. Among the social determinants of physical and mental health in populations of older adults, strong social networks with high levels of social support generally represent a protective factor for maintaining good health and quality of life in old age. ${ }^{1-3}$ Different forms of social support are related to a variety of physical and mental health outcomes. ${ }^{4}$ For example, older adults may receive emotional support from their loved ones and feel useful when they are involved in their lives. A study of over 1200 community-dwelling older adults in Spain concluded that high emotional support was positively associated with physical and mental health. ${ }^{5}$ Another study of over 3400 older adults in the USA confirmed that satisfaction with social support is related to good self-rated health (SRH). ${ }^{6}$ Moreover, a 
systematic review of 51 studies with different age groups also revealed significant protective effects of perceived emotional support in relation to depression. ${ }^{7}$ Finally, good quality of life has also been related to social support in older adults. $^{8}$

Berkman and Glass ${ }^{3}{ }^{9}$ proposed a conceptual model of the influence of social networks and support on health status, which recognised that individual social networks depend on the social and cultural context where individuals live. As such, the impact of social relations on various indicators of health and well-being appears to vary depending on the nature of social ties (eg, friends, children, family members and partner) and the quality of the relationships, a complexity that calls for further study. ${ }^{10}$ For example, recent research in the USA suggests that social support from friends becomes an important predictor of perceived health among older adults, particularly when compared with younger cohorts for whom family support seems more important. ${ }^{11}$ In addition, the majority of research about the impact of social support on health and quality of life has been carried out in specific populations in North America and in Western Europe, ${ }^{12} 13$ although what constitutes good social support may vary in relation to the social values and norms of regions and countries. To this day, we have limited knowledge about the relationships between social support and health outcomes beyond these particular socio-cultural contexts. The different social norms and expectations surrounding social relations in cross-cultural samples of older adults further complicate this field of study. ${ }^{14}{ }^{15}$ Research across ethnic or racial groups in the USA ${ }^{16-18}$ demonstrated differences in correlates of health and quality of life among these groups, which suggest that there will be differences in different regions of the world. ${ }^{19} 20$ Comparisons across populations allow us to detect the features of the social environment that affect most (or all) individuals in a population and have therefore little variance (or are invariant) within that population. ${ }^{21}$

The objective of this study is to examine associations between emotional support and self-reported health, depression and quality of life, which are important indicators of overall well-being among older adults from Canada and Latin America. The three study outcomes were chosen because of their importance in terms of the longevity and well-being of older adults. SRH is one of the stronger predictors of mortality in cohorts of older adults in Canada ${ }^{22}$ and in Brazil ${ }^{23}$ and according to multiple international studies. ${ }^{24}{ }^{25}$ Depression in later life is a strong risk factor for disability ${ }^{26}$ and cognitive decline, ${ }^{27}$ and a frequent outcome for chronic diseases. ${ }^{28}$ Self-reported quality of life is an encompassing index of well-being in old age and of successful ageing. ${ }^{29}$ The study sites were four middle-sized cities: Kingston (Ontario) and Saint-Hyacinthe (Quebec) in Canada, Manizales in the Andean Mountains of Colombia and Natal in North East Brazil. The sites were selected to capture a diversity of experiences in old age, particularly different social and gender relations, as well as levels of economic security. Moreover, we used a new validated measurement tool that assesses the emotional support associated with different social ties, which will enable us to detect cross-cultural differences in the links between social relations and indicators of health and well-being. ${ }^{30}$ In light of existing literature, we posit the following hypotheses regarding the relationship between emotional support and the outcomes of interest. We expect that more emotional support will generally be associated with better health, mood and quality of life in older adults. We also expect that different sources of support will have different effects on the outcomes, and that these associations will vary cross-culturally in North America when compared to Latin America.

\section{METHODS}

\section{Study population and recruitment methods}

For this study, we analysed baseline data from the International Mobility in Aging Study (IMIAS), which were collected in 2012. Rationale and methods have been described in previous publications. ${ }^{31}$ Briefly, the sample includes 400 community-dwelling adults (200 men and 200 women) aged 65-74 years at each of the four sites, for a total sample of 1600 . The sample sizes were established as part of the original IMIAS study and were deemed sufficient to capture gender differences in mobility across sites. Participants were recruited randomly from the patient lists of primary care providers. At the two Latin American sites, participants were contacted directly by researchers and there was a response rate close to $100 \%$. Owing to requirements of the ethical review boards, participants could not be contacted directly in Canada. They were invited to participate in the study through a letter from their primary care provider, and then had to contact our field researcher to enter the study. Approximately $30 \%$ of those receiving the letter contacted us to participate, and $95 \%$ of them participated in the study. At all sites, study procedures were carried out at the participants' home. Study material and questionnaires were available in the local languages: English, French, Spanish and Portuguese.

\section{Ethical requirements}

This project was approved by the institutional review boards of the relevant health centres where the study was conducted, and the overall study is overseen by the ethical review board of the Research Centre of the Centre Hospitalier de l'Université de Montréal (CRCHUM).

\section{Measures}

\section{Self-rated health}

Participants were asked, 'Would you rate your health as very good, good, fair, poor or very poor?'. SRH was dichotomised as good if respondents answered 'very good' or 'good', and poor if respondents answered 
'fair', 'poor' or 'very poor'. ${ }^{32}$ The validity of this measurement item was demonstrated in our study population through a significant linear association between mean score of the Short Physical Performance Battery and ordinal categories of SRH. ${ }^{33}$ Four participants were excluded because of missing values.

\section{Depressive symptoms}

In this study, we defined depression as having a score of 16 and above on the Centre for Epidemiological Studies Depression (CES-D) scale, which is indicative of a probable diagnosis of depression. ${ }^{34}$ The CES-D scale has been used extensively in populations of older adults and encompasses negative affect, positive affect, somatic symptoms and interpersonal problems. ${ }^{35}$ Studies have demonstrated its validity and reliability in French, ${ }^{36}$ in Spanish $^{37}$ and in Portuguese, ${ }^{38}$ as well as in low-income settings. ${ }^{39}$ There were no missing values.

\section{Quality of life}

Quality of life was assessed with a visual analogue scale (VAS). Participants were asked to indicate their quality of life in the preceding 2 weeks on a continuous line that went from the worst possible quality to the best possible quality. Their answers were then converted into a number from 1 to 10 based on their position on the line. VAS measures of quality of life are valid and reliable when used as a dependent variable to assess global quality of life. ${ }^{40}$ Given the distribution of quality of life across sites, a score higher or equal to 8 out of 10 represents a good quality of life (this corresponds roughly to $70 \%$ of the studied Canadian population), in agreement with research showing that $\sim 75 \%$ of older adults consider that they have a good or very good quality of life. ${ }^{8}$ There were no missing values.

\section{Social support}

Social support was measured for different social ties, namely with friends, family members, children and partner. To this effect, we used a scale that was developed and validated by members of the IMIAS team using confirmatory factor analysis, called the social support and network scale (SSSN-IMIAS) ${ }^{30}$ based on previous scales. ${ }^{1}{ }^{42}$ Factor analysis demonstrated satisfactory goodness of fit and consistent validity in the study population. ${ }^{30}$ This scale focuses on the emotional support and feelings of usefulness provided by the four above cited types of social ties. Five Likert scale questions about social support were included in the IMIAS-SSSN for each type of social tie. For example, participants were asked if they felt loved by their friends, if they felt that their friends listen to them when they talk about their problems, if they felt useful for their friends, how often they helped their friends and if they felt they play an important role in their friends' lives. The maximum total score for social support is 20 for each type of social tie. There were wide variations in the existence and frequency of social ties cross-culturally. As an illustration, while most Canadians reported having friends only half of the Natal sample reported this tie. Given this, social support was coded as ranking in the lowest quartile of social support. Low social support is used as the reference category throughout the analyses, and compared with those without the social tie and those reporting social support above the lowest quartile. Missing data were excluded, leaving a total sample size of 1582 participants. They did not follow a specific pattern across study sites and represented fewer than five respondents per study site, per social tie.

\section{Control variables}

The confounding variables that were controlled for in this study were selected according to the literature on socioeconomic and functional determinants of SRH, depression and quality of life in older adults. Among them, age, gender, education and income have been identified as potential strong confounders in the associations of self-reported measures of physical and mental health and quality of life with social support. Finally, disability in activities of daily living (ADL) was considered a potential confounder because this type of severe disability has known effects on SRH and depression and it is a strong determinant of quality of life. ADL disability has been shown to be related to social networks and support. ${ }^{43}$ Education was measured as a categorical variable, in terms of having less than a high school degree, having a high school diploma or having postsecondary education. Income sufficiency was also measured as a categorical variable; respondents could indicate that their income was insufficient, sufficient or very sufficient to cover their basic needs. ADL disability was measured as a binary variable to capture the presence of any difficulty in conducting any of a list of six basic activities of daily living (walking across a room, bathing, getting dressed, getting up, eating and going to the bathroom).

\section{Statistical analyses}

We examined descriptive statistics and then constructed several models using Poisson multiple regression with robust covariance to test our hypotheses with each outcome variable. While logistic regression is recommended to estimate the occurrence of rare events, that is, those occurring $<10 \%$ of the time, Poisson regression with robust covariance is preferred for cross-sectional studies of binary outcomes that are common, because the confidence intervals (CIs) are more conservative and prevalence ratios (PR) are easier to interpret and disseminate. ${ }^{44} 45$ The analyses were carried out following the hypotheses tested. We first modelled the data together to examine the associations between sources of social support and the outcomes of interest. To test the heterogeneity of the associations between considered risk factors and SRH, depressive symptoms and quality of life across research sites, we conducted two Omnibus tests of the interactions of all social support sources with each outcome (six models) with research site and then with 
gender at a level of significance of 0.05 , without including potential covariates. Since these associations were statistically significant for the Canadian data and the Latin American data, we proceeded by analysing these separately. We finally tested the impact of confounding variables on models developed at the different sites to assess whether the associations between social support and the outcomes of interest remained statistically significant despite controlling for age, gender, income sufficiency, level of education and disability in activities of daily living.

\section{RESULTS}

There are major differences between the Canadian and Latin American study samples in terms of sociodemographic variables, ADL disability, SRH, depression and quality of life. In table 1, the Canadian sample has significantly higher levels of education and income sufficiency. While few people had less than secondary education or had insufficient income to cover basic needs in Canada, the majority of Latin American older adults had not finished secondary education and had insufficient income to cover basic needs. These are very important aspects of the social context to consider when assessing the health of ageing populations. ADL disability was significantly more prevalent in Latin America, affecting $26 \%$ of older adults in Manizales and $31 \%$ in Natal compared with $22 \%$ in Kingston and $16 \%$ in Saint-Hyacinthe.

Good SRH was more common in Canada, with the highest value among men living in Kingston $(87.50 \%)$ and the lowest one among women living in Natal (22.93\%) (table 2). The majority of Latin American participants reported being in poor health. Depression was less frequent among Canadian participants and was higher among women, overall, but especially at Latin American sites. Although less pronounced than the distribution of SRH, quality of life followed a similar trend, with the majority of Canadian respondents reporting a high quality of life and the majority of Latin American older adults reporting a low quality of life. Correlations between the outcome measures were moderate: between quality of life and $\mathrm{SRH}$, it was 0.35 ; between quality of life and depression, it was 0.29 and between depression and SRH, it was 0.36 .

The differences between the distributions of social support variables across sites are also worth noting (table 3). While fewer than $6 \%$ of Canadian participants reported having no friends, this proportion reached $25 \%$ in Manizales and nearly $50 \%$ in Natal. Support from partner was precluded for those without a partner. This was of particular importance in Manizales, where $49.50 \%$ had no partner. The proportions of low social support were similar across sites because the variable was constructed as a site-specific lowest quartile among those who had the specific social tie (friends, children, family or spouse). Low social support is therefore a contextspecific variable, whereby support is considered low in comparison with local societal norms. The variable of interest is therefore exposure to less social support than the social norm at the specific study sites.

We first pooled all of the data together to examine relationships between different sources of social support and each outcome of interest. Then, we examined how context (research site) modified the association between social support and the three outcomes. Significant interactions were found between the social support provided by family members and Canadian versus Latin American study sites (comparison of models with interaction terms and without, SRH: $\chi^{2}=10.86, \quad \mathrm{p}=0.004$; depression: $\chi^{2}=12.57, p=0.002$ and quality of life: $\chi^{2}=5.27, p=0.072$ ).

Table 1 Descriptive statistics of study samples

\begin{tabular}{|c|c|c|c|c|c|c|c|c|c|}
\hline & \multicolumn{2}{|c|}{ Kingston } & \multicolumn{2}{|c|}{ Saint-Hyacinthe } & \multicolumn{2}{|c|}{ Manizales } & \multicolumn{2}{|c|}{ Natal } & \multirow[b]{2}{*}{ p Value $\chi^{2}$} \\
\hline & $\mathbf{N}$ & $\%$ & $\mathbf{N}$ & $\%$ & $\mathbf{N}$ & $\%$ & $\mathbf{N}$ & $\%$ & \\
\hline Gender & & & & & & & & & 0.887 \\
\hline Male & 186 & 46.73 & 191 & 47.63 & 198 & 49.50 & 192 & 47.76 & \\
\hline Female & 212 & 53.27 & 210 & 52.37 & 202 & 50.50 & 210 & 52.24 & \\
\hline Age & & & & & & & & & 0.011 \\
\hline $65-69$ years & 223 & 56.03 & 255 & 63.59 & 214 & 53.50 & 215 & 53.48 & \\
\hline $70-74$ years & 175 & 43.97 & 146 & 36.59 & 186 & 46.50 & 187 & 46.52 & \\
\hline Education & & & & & & & & & 0.000 \\
\hline Primary/illiterate & 38 & 9.60 & 113 & 28.46 & 335 & 83.75 & 360 & 89.78 & \\
\hline Secondary & 50 & 12.63 & 82 & 20.65 & 20 & 5.00 & 24 & 5.99 & \\
\hline Postsecondary & 308 & 77.78 & 202 & 50.88 & 45 & 11.25 & 17 & 4.24 & \\
\hline Income sufficiency & & & & & & & & & 0.000 \\
\hline Insufficient & 21 & 5.28 & 30 & 7.48 & 285 & 71.25 & 298 & 74.13 & \\
\hline Sufficient & 134 & 33.67 & 194 & 48.38 & 96 & 24.00 & 88 & 21.89 & \\
\hline Very sufficient & 243 & 61.06 & 177 & 44.14 & 19 & 4.75 & 16 & 3.98 & \\
\hline $\begin{array}{l}\text { Prevalence of ADL } \\
\text { disability }\end{array}$ & 90 & 22.61 & 64 & 15.96 & 106 & 26.50 & 125 & 31.09 & 0.000 \\
\hline
\end{tabular}


Table 2 Prevalence of good self-rated health, depression and high quality of life (\%)

\begin{tabular}{|c|c|c|c|c|c|c|c|c|}
\hline & \multicolumn{2}{|c|}{ Kingston } & \multicolumn{2}{|c|}{ Saint-Hyacinthe } & \multicolumn{2}{|c|}{ Manizales } & \multicolumn{2}{|l|}{ Natal } \\
\hline & Men & Women & Men & Women & Men & Women & Men & Women \\
\hline Good self-rated health & 87.50 & 83.89 & 83.77 & 81.43 & 55.05 & 45.54 & 35.42 & 22.97 \\
\hline Depression & 5.38 & 10.85 & 6.28 & 12.86 & 17.68 & 28.71 & 6.25 & 31.90 \\
\hline High quality of life & 75.81 & 70.75 & 74.75 & 69.52 & 40.91 & 52.48 & 44.79 & 42.38 \\
\hline
\end{tabular}

We also tested for interactions with gender, and although it is a significant confounder in Latin America, none of the interaction terms between social support and gender were significant. Men and women were therefore modelled together.

To better understand these differences between sites, we modelled the Canadian and Latin American data separately. Table 4 presents the PR obtained in Canada when testing the relationship between all sources of social support and the three outcome variables, first unadjusted and then when controlling for age, gender, site, level of education, income sufficiency as well as disability. High support from friends and not having a spouse are significantly associated with poorer health in Canada, in the unadjusted and the adjusted models. Similarly, not having friends and not having a partner yield a higher PR of depression, but this effect disappears after adding the control variables about socioeconomic status (staggered inclusion of variables in regression models, not shown here). The associations are not significant for quality of life, but the absence of partner again appears to be relevant for quality of life in the unadjusted model with our sample of older Canadian adults. It is noteworthy that among older Canadians, social support from family members and children is not related to any of the three outcomes, and that the quality of the relationships themselves does not seem to have an impact. In other words, those with a better relationship with friends and who have a partner do report better outcomes. For partner, significant differences only emerge between those with the specific social tie and those without.

The results from the Latin American models were at odds with the Canadian ones (table 5). High levels of social support by family members were associated with better health and although the significance of the associations was lost after full adjustment by covariates, the size of the regression coefficients changed very little. High social support from partner was also associated with good health, but this relationship also disappeared after controlling for gender and site (staggered entry of variables in the analyses, not shown here). The results for depression demonstrated large effects despite all control variables; a high level of social support from children, family members and partner was all related with a lower prevalence of depressive symptoms. With respect to quality of life, a high level of social support from children and partner remained significant after controlling for confounding variables. Across the three outcome variables, there were no significant differences between those without social ties and those with poor levels of social support. To assess whether the associations of quality of life with social support were independent from older adults' physical and mental health, we fitted

Table 3 Distribution of social support (\%)

\begin{tabular}{|c|c|c|c|c|c|}
\hline & Kingston & Saint-Hyacinthe & Manizales & Natal & p Values ${ }^{\star} \chi^{2}$ \\
\hline Social support friends & & & & & 0.000 \\
\hline No friends & 2.76 & 5.74 & 24.75 & 48.51 & \\
\hline Low friend support† & 25.88 & 24.44 & 21.25 & 14.93 & \\
\hline High friend support & 71.36 & 69.83 & 54.00 & 36.57 & \\
\hline Social support children & & & & & 0.034 \\
\hline No children & 11.56 & 11.72 & 10.00 & 6.22 & \\
\hline Low children support† & 27.89 & 22.94 & 28.00 & 24.63 & \\
\hline High children support & 60.55 & 65.34 & 62.00 & 69.15 & \\
\hline Social support family & & & & & 0.014 \\
\hline No family & 8.79 & 3.99 & 4.00 & 4.73 & \\
\hline Low family support† & 26.88 & 25.69 & 25.00 & 29.85 & \\
\hline High family support & 64.32 & 70.32 & 71.00 & 65.42 & \\
\hline Social support partner & & & & & 0.000 \\
\hline No partner & 37.19 & 29.43 & 49.50 & 31.59 & \\
\hline Low partner support† & 20.85 & 22.94 & 12.75 & 22.89 & \\
\hline High partner support & 41.96 & 47.63 & 37.75 & 45.52 & \\
\hline
\end{tabular}

${ }^{*}$ Comparison between sites.

†Defined as the lowest quartile of the social support score at each specific site. 
Table 4 Prevalence ratios of good self-rated health, depression and high quality of life in Canada

\begin{tabular}{|c|c|c|c|c|c|c|}
\hline & \multicolumn{2}{|c|}{ Good self-rated health } & \multicolumn{2}{|l|}{ Depression } & \multicolumn{2}{|l|}{ High quality of life } \\
\hline & Unadjusted (Cl) & Adjusted (Cl) & Unadjusted (Cl) & Adjusted (Cl) & Unadjusted (Cl) & Adjusted (Cl) \\
\hline \multicolumn{7}{|l|}{ Social support friends } \\
\hline $\begin{array}{l}\text { No friends } \\
\text { Low support friends (ref) }\end{array}$ & 0.76 (0.58 to 0.99$)$ & 0.80 (0.62 to 1.03$)$ & 2.49 (1.22 to 5.05$)$ & 1.55 (0.79 to 3.05$)$ & 0.74 (0.53 to 1.01$)$ & 0.79 (0.59 to 1.05$)$ \\
\hline High support friends & 1.10 (1.02 to 1.19$)$ & 1.09 (1.01 to 1.18$)$ & 0.69 (0.42 to 1.15$)$ & 0.67 (0.40 to 1.11$)$ & 1.04 (0.93 to 1.15$)$ & 1.03 (0.93 to 1.13 ) \\
\hline \multicolumn{7}{|l|}{ Social support family } \\
\hline $\begin{array}{l}\text { No family } \\
\text { Low support family (ref) }\end{array}$ & .94 (0.82 to 1.09$)$ & 0.90 (0.79 to 1.05$)$ & 1.31 (0.62 to 2.76$)$ & 1.30 (0.63 to 2.69$)$ & 0.90 (0.71 to 1.14$)$ & 0.86 (0.68 to 1.08$)$ \\
\hline High support family & 1.00 (0.93 to 1.07$)$ & 0.98 (0.91 to 1.05$)$ & $0.78(0.47$ to 1.28$)$ & 0.75 (0.47 to 1.22$)$ & $1.12(1.00$ to 1.25$)$ & 1.09 (0.98 to 1.21$)$ \\
\hline \multicolumn{7}{|l|}{ Social support children } \\
\hline $\begin{array}{l}\text { No children } \\
\text { Low support children (ref) }\end{array}$ & $1.02(0.91$ to 1.14$)$ & 1.01 (0.91 to 1.12$)$ & 0.98 (0.54 to 1.79$)$ & 1.08 (0.61 to 1.90$)$ & 1.06 (0.89 to 1.26$)$ & 1.04 (0.89 to 1.22 ) \\
\hline High support children & 1.00 (0.93 to 1.08$)$ & 1.00 (0.92 to 1.08$)$ & 0.63 (0.38 to 1.05$)$ & 0.65 (0.38 to 1.08$)$ & 1.07 (0.96 to 1.20$)$ & 1.06 (0.95 to 1.19$)$ \\
\hline Social support partner & & & & & & \\
\hline $\begin{array}{l}\text { No partner } \\
\text { Low support partner (ref) }\end{array}$ & 0.84 (0.77 to 0.92$)$ & 0.90 (0.82 to 0.98$)$ & 2.23 (1.25 to 3.98$)$ & 1.36 (0.78 to 2.37$)$ & 0.85 (0.74 to 0.97$)$ & 0.93 (0.82 to 1.06$)$ \\
\hline High support partner & 0.99 (0.92 to 1.07$)$ & 1.00 (0.93 to 1.07$)$ & $0.60(0.29$ to 1.24$)$ & 0.64 (0.32 to 1.28$)$ & 1.09 (0.97 to 1.22$)$ & 1.10 (0.99 to 1.22$)$ \\
\hline
\end{tabular}

Table 5 Prevalence ratios of good self-rated health, depression and high quality of life in Latin America

\begin{tabular}{|c|c|c|c|c|c|c|}
\hline & \multicolumn{2}{|c|}{ Good self-rated health } & \multicolumn{2}{|l|}{ Depression } & \multicolumn{2}{|l|}{ High quality of life } \\
\hline & Unadjusted (Cl) & Adjusted (Cl) & Unadjusted (Cl) & Adjusted (Cl) & Unadjusted (Cl) & Adjusted (Cl) \\
\hline \multicolumn{7}{|l|}{ Social support friends } \\
\hline $\begin{array}{l}\text { No friends } \\
\text { Low support friends (ref) }\end{array}$ & 1.04 (0.80 to 1.34$)$ & 1.26 (0.99 to .1.63) & 1.07 (0.75 to 1.52$)$ & 0.97 (0.68 to 1.37 ) & 0.81 (0.64 to 1.04$)$ & 0.83 (0.65 to 1.06$)$ \\
\hline High support friends & 1.04 (0.81 to 1.34$)$ & 1.08 (0.85 to 1.38$)$ & 1.25 (0.88 to 1.78$)$ & 1.10 (0.78 to 1.54$)$ & 1.15 (0.92 to 1.44$)$ & $1.13(0.91$ to 1.40$)$ \\
\hline \multicolumn{7}{|l|}{ Social support family } \\
\hline $\begin{array}{l}\text { No family } \\
\text { Low support family (ref) }\end{array}$ & 0.83 (0.46 to 1.48$)$ & 1.00 (0.59 to 1.69$)$ & 1.25 (0.80 to 1.93$)$ & 0.90 (0.60 to 1.37 ) & 1.21 (0.82 to 1.79$)$ & 1.27 (0.84 to 1.92$)$ \\
\hline High support family & 1.35 (1.06 to 1.72$)$ & 1.25 (0.99 to 1.58$)$ & 0.64 (0.48 to 0.86$)$ & 0.63 (0.48 to 0.83$)$ & 1.23 (0.98 to 1.53$)$ & 1.15 (0.93 to 1.44$)$ \\
\hline \multicolumn{7}{|l|}{ Social support children } \\
\hline $\begin{array}{l}\text { No children } \\
\text { Low support children (ref) }\end{array}$ & 0.98 (0.65 to 1.48$)$ & $0.89(0.61$ to 1.31$)$ & 0.87 (0.59 to 1.30$)$ & 1.12 (0.75 to 1.68$)$ & 1.52 (1.07 to 2.16$)$ & 1.39 (0.99 to 1.94$)$ \\
\hline High support children & 1.18 (0.93 to 1.51$)$ & 1.20 (0.95 to 1.52$)$ & 0.56 (0.41 to 0.76$)$ & $0.60(0.45$ to 0.80$)$ & 1.66 (1.28 to 2.14$)$ & 1.54 (1.20 to 1.99$)$ \\
\hline Social support partner & & & & & & \\
\hline $\begin{array}{l}\text { No partner } \\
\text { Low support partner (ref) }\end{array}$ & 1.22 (0.91 to 1.63$)$ & 1.19 (0.91 to 1.57$)$ & 1.08 (0.80 to 1.46$)$ & 0.86 (0.65 to 1.15$)$ & 1.17 (0.91 to 1.52$)$ & 1.20 (0.94 to 1.55$)$ \\
\hline High support partner & $1.44(1.08$ to 1.90$)$ & $1.21(0.93$ to 1.57$)$ & 0.45 (0.30 to 0.68$)$ & 0.57 (0.31 to 0.77$)$ & $1.31(1.02$ to 1.69$)$ & 1.31 (1.03 to 1.67$)$ \\
\hline
\end{tabular}


regression equations for Canada and Latin America, using quality of life as the dependent variable and adding SRH or depression as a potential confounder. Changes in the coefficients of social support variables were negligible, demonstrating that the associations between quality of life and social support are independent of any physical or mental health problems (data not shown).

\section{DISCUSSION}

We examined the associations between emotional support and SRH, depression and quality of life in older adults aged between 65 and 74 years residing in two Canadian and two Latin American cities. First, among Canadian and Latin American participants, there were positive associations between either the presence of social ties or perceived emotional support and SRH, depression and quality of life. The association between social support and health, mood and quality of life differed cross-culturally according to its source. Among Canadian participants, protective associations were found between good health and less depression and high levels of support from friends and having a partner. No effect was observed for the quality of the support from partner, children or family, demonstrating that they did not play a role in health, depression or quality of life. Among Latin American participants, the strongest associations were seen when support came from extended family, children and partner, whereas support from friends did not play a significant role. In fact, among Latin Americans, having high levels of social support from family and partner was related to good health, and having high support from children was also related to less depression and better quality of life. Quality of life was related to receiving high levels of support from the partner, and those with poor support from children appeared to have worse quality of life than those without children. We conclude that aside from the importance of relationships with friends, in Canada, the presence of a partner is more important than the quality of support, which is different from the results in Latin America where not merely the presence of the social tie, but the levels of support from family members, children and partner are significantly associated with older adults' health and well-being.

These results confirm and extend previous research conducted in Europe comparing social support in five Mediterranean countries with seven countries of Northern Europe. ${ }^{15}$ Litwin reported that family support is more important in Mediterranean countries where there are more household exchanges. These observations are in agreement with previous research conducted in Canada, ${ }^{32} \mathrm{Cuba}^{46}$ and Spain. ${ }^{5}$ Moreover, comparing two francophone older Canadian populations, one from a working class neighbourhood population of Montreal, and the other from the middle class city of Moncton, New Brunswick, Zunzunegui et $a l^{22}$ found that in
Montreal, having family and children was associated with good health, whereas having low support from children was associated with poor health. Networks of friends played a role only for those with good physical and cognitive function. In Moncton, the associations were different because only relationships with friends seemed to play a role in health. The authors concluded that support from children was more salient in socially and materially deprived areas than in more affluent environments.

These results suggest that among our Canadian participants, the effects of social support on health and well-being could be linked to a protection against social isolation. We propose that in high-income countries like Canada, where friends are associated with leisure activities and family ties may lead to unwanted responsibilities and potential conflicts, friends could be more beneficial for health. ${ }^{47}$ Levels of social capital are high in Canada and society provides the services that family members provide in other cultures. ${ }^{48}$ In addition, Canadians have a relatively strong system of public and private social services and old age pensions, which provide some economic security to older adults. Consequently, there is relatively less need to rely on family. It appeared that the quality of the social support provided was more important in Latin America, especially when this support came from family members, children and cohabiting partner. In fact, older adults in Latin America appear to place more emphasis on emotional support from their children, and social contact and affection with grandchildren has been found to influence their sense of well-being. ${ }^{49}$ Latin American older adults live in societies with strong family intergenerational interdependence but limited economic security, social protection and social services. ${ }^{50}$ Social integration in society occurs within the family around which the social life pivots. ${ }^{51}{ }^{52}$ Family interdependence means that support flows between generations in multigenerational households. Previous results on social support and depression in Cuba coincide with our findings from Southern Brazil, whereby receiving help from children and extended family is associated with the lowest depression rates. ${ }^{46} 53$ Results about the beneficial effects of friends on health and quality of life in this study confirm previous results from longitudinal ageing research conducted in the USA and Northern Europe.

Our research contributes to the literature about social relations and health outcomes among older adults by demonstrating that the sources of social support that are relevant to the physical and mental health and quality of life vary according to the socioeconomic and cultural characteristics of the population. Today more than two-thirds of older adults live in middle-income and lowincome countries where social protection for older adults is weak and older adults' well-being depends on family exchanges and solidarity. Our results for Latin America contribute to the limited literature on social support and health in that region and can be helpful in inspiring social policies. In particular, emerging economies, such as Brazil, have recently legislated universal 
old age pensions and healthcare for older adults. These universal protection programmes may have further increased interfamilial dependence. ${ }^{54}$ For example, in periods of economic crises, the household's largest source of revenue may come from the pension of the older members of the family and many older adults help with house chores and care of grandchildren in a system of family exchange across generations. Social networks and support represent an important determinant of older population's health and well-being in Latin America and possibly in other regions of the world where family interdependence is highly valued.

\section{Strengths and limitations of the study}

The cross-sectional nature of this study imposes restrictions in establishing the temporal sequence of the associations between social support, health and quality of life. It is possible that those who have the poorest health and quality of life are unable to mobilise social support from their networks. However, some of these results continue to be significant even after controlling for disability, establishing the associations independently of the presence of disability. The latest longitudinal research also suggests that the associations between social support and health indicators may be bidirectional and may change in strength over the life course. ${ }^{55}$ Second, there are challenges inherent in cross-cultural research, such as the difficulty of interpreting findings across very different cultural contexts. ${ }^{56}$ While some authors do not recommend combining data sets across populations because of uncertainty regarding the equivalence of covariance matrices, our work addressed these limitations by validating the social support scales with factor analysis in the different cultural contexts ${ }^{30}$ and by involving a multicultural research team in the study design and analysis. Our results nonetheless remain preliminary and need further confirmation in Latin American populations and in other settings with emerging economies and changing levels of social protection and family norms.

Moreover, the relatively low response rates among the Canadian samples raise questions about external validity. We addressed this issue in previous publications reporting that according to census data, the Saint-Hyacinthe sample is comparable to the population of the same age group in the selected cities in terms of education, income and education and that the Kingston sample is relatively more highly educated. Kingston is, nevertheless, similar to the sample in Saint-Hyacinthe in terms of blood pressure, ${ }^{57} \mathrm{C}$ reactive protein, ${ }^{58}$ physical function indicators $^{31}$ and distributions of SRH, depression and quality of life as reported here. It is nevertheless important to mention that the study samples are limited to older adults registered with a primary care provider, and that study samples in Canada are likely to be less depressed than the general population of older adults, given that they had to contact the research coordinator to participate in the study. As far as we know, the coverage of family medicine at local medical clinics (Canada) and neighbourhood primary health centres (Brazil) is higher than $90 \%$ for the population aged 65-74 years residing in the participating cities. ${ }^{59}$ Only Manizales (Colombia) does not have universal coverage for healthcare, but a high percentage of Colombian older adults (around $82 \%)$ are covered by the Public Health Insurance. ${ }^{60}$ Outside of Canada, response rates were very high, close to $100 \%$. Therefore, we have reasons to believe that these samples are representative of the population registered at those local health centres. Among the strengths of this research, we need to mention the rigorous survey methodology preceded by two pilot studies, the high response rates in Manizales and Natal, and the validity of the social support scales. We also examined the same relationships with identical measures and data collection protocols in the four populations, which make cross-site comparisons rigorous and valid.

In conclusion, the impact of social support is closely linked to different societal and cultural norms. The effects of social support on physical and mental health and on quality of life depend on the sources of this support and vary by social context. Social interventions to mobilise social support to promote the well-being and health of older populations need to take these contextual determinants into consideration.

\section{Author affiliations}

${ }^{1}$ Department of Social and Preventive Medicine, Université de Montréal, Public Health Research Institute (IRSPUM), Montreal, Quebec, Canada

${ }^{2}$ Department of Social and Preventive Medicine, Université de Montréal, Montreal, Quebec, Canada

${ }^{3}$ Department of Public Health Sciences, Queen's University, Kingston, Ontario, Canada

${ }^{4}$ Faculty of Health Sciences, Research Group on Geriatrics and Gerontology, International Association of Gerontology and Geriatrics Collaborative Centre, University of Caldas, Manizales, Colombia

${ }^{5}$ Department of Family Medicine and Public Health Sciences, Queen's University, Kingston, Ontario, Canada

${ }^{6}$ Department of Social and Preventive Medicine, Public Health Research Institute (IRSPUM), Université de Montréal, Montreal, Quebec, Canada

Contributors EB elaborated the study design and performed the analysis of the data in close collaboration with TA and MVZ. AV, CLC and SPP provided critical feedback during the study design, analysis, interpretation of findings and writing of the final manuscript.

Funding The IMIAS study was supported by an operating grant from the Canadian Institutes of Health Research (CIHR). The first author received a postdoctoral fellowship from the Fonds de recherche du Québec- Santé (FRQ-S) to carry out this work.

Competing interests All authors have completed the ICMJE uniform disclosure form at http://www.icmje.org/coi_disclosure.pdf and declare: funding from the organisations listed above; no financial relationships with any organisations that might have an interest in the submitted work in the previous 3 years; no other relationships or activities that could appear to have influenced the submitted work.

Ethics approval Centre de recherche du Centre Hospitalier de l'Université de Montréal (CRCHUM).

Provenance and peer review Not commissioned; externally peer reviewed.

Data sharing statement The entire data set from the International Mobility in Aging Study is available for researchers. For access, please contact the principal investigator Professor Maria Victoria Zunzunegui at this email address: maria.victoria.zunzunegui@umontreal.ca 
Open Access This is an Open Access article distributed in accordance with the Creative Commons Attribution Non Commercial (CC BY-NC 4.0) license, which permits others to distribute, remix, adapt, build upon this work noncommercially, and license their derivative works on different terms, provided the original work is properly cited and the use is non-commercial. See: http:// creativecommons.org/licenses/by-nc/4.0/

\section{REFERENCES}

1. Seeman TE, Bruce ML, McAvay GJ. Social network characteristics and onset of ADL disability: MacArthur studies of successful aging J Gerontol B Psychol Sci Soc Sci 1996;51B:S191-200.

2. Newsom JT, Schulz R. Social support as a mediator in the relation between functional status and quality of life in older adults. Psychol Aging 1996;11:34-44.

3. Berkman LF, Krishna A. Social network epidemiology. In: Berkman LF, Kawachi I, Glymour MM, eds. Social epidemiology. Oxford: Oxford University Press, 2014:234-89.

4. Ashida S, Heaney CA. Differential associations of social support and social connectedness with structural features of social networks and the health status of older adults. J Aging Health 2008;20:872-93.

5. Zunzunegui MV, Béland F, Otero A. Support from children, living arrangements, self-rated health and depressive symptoms of older people in Spain. Int J Epidemiol 2001;30:1090-9.

6. White AM, Philogene GS, Fine L, et al. Social support and self-reported health status of older adults in the United States. Am J Public Health 2009;99:1872-8.

7. Santini Zl, Koyanagi A, Tyrovolas S, et al. The association between social relationships and depression: a systematic review. J Affect Disord 2015;175:53-65.

8. Bowling A, Gabriel Z, Dykes J, et al. Let's ask them: a national survey of definitions of quality of life and its enhancement among people aged 65 and over. Int J Aging Hum Dev 2003;56:269-306.

9. Berkman LF, Glass T, Brissette I, et al. From social integration to health: Durkheim in the new millennium. Soc Sci Med 2000;51:843-57.

10. Craigs CL, Twiddy M, Parker SG, et al. Understanding causal associations between self-rated health and personal relationships in older adults: a review of evidence from longitudinal studies. Arch Gerontol Geriatr 2014;59:211-26.

11. Heinze JE, Kruger DJ, Reischl TM, et al. Relationships among disease, social support, and perceived health: a lifespan approach. Am J Community Psychol 2015;56:268-79.

12. Holt-Lunstad J, Smith TB, Layton JB. Social relationships and mortality risk: a meta-analytic review. PLoS Med 2010;7:e1000316.

13. Pinquart $M$, Duberstein $P R$. Associations of social networks with cancer mortality: a meta-analysis. Crit Rev Oncol Hematol 2010;75:122-37.

14. Litwin $\mathrm{H}$. Social networks and self-rated health: a cross-cultura examination among older Israelis. J Aging Health 2006;18:335-58.

15. Litwin $\mathrm{H}$. Social networks and well-being: a comparison of older people in Mediterranean and non-Mediterranean countries. J Gerontol B Psychol Sci Soc Sci 2010;65B:599-608.

16. Ren XS, Amick BC. Race and self assessed health status: the role of socioeconomic factors in the USA. J Epidemiol Community Health 1996;50:269-73.

17. Russell D, Taylor J. Living alone and depressive symptoms: the influence of gender, physical disability, and social support among Hispanic and non-Hispanic older adults. J Gerontol B Psychol Sci Soc Sci 2009;64B:gbn002-104.

18. Sheffler J, Sachs-Ericsson N. Racial differences in the effect of stress on health and the moderating role of perceived social support. J Aging Health 2015. [Epub ahead of print]. doi:10.1177/0898264315618923

19. Grant RL, Bowling A. Challenges in comparing the quality of life of older people between ethnic groups, and the implications for national well-being indicators: a secondary analysis of two cross-sectional surveys. Health Qual Life Outcomes 2011;9:109.

20. Williams ED, Tillin T, Whincup $P$, et al. Ethnic differences in disability prevalence and their determinants studied over a 20 -year period: a cohort study. PLOS ONE 2012;7:e45602.

21. Schwartz S, Meyer IH. Mental health disparities research: the impact of within and between group analyses on tests of social stress hypotheses. Soc Sci Med 2010;70:1111-8.

22. Mossey JM, Shapiro E. Self-rated health: a predictor of mortality among the elderly. Am J Public Health 1982;72:800-8.

23. Lima-Costa MF, Cesar CC, Chor D, et al. Self-rated health compared with objectively measured health status as a tool for mortality risk screening in older adults: 10-year follow-up of the Bambui Cohort Study of Aging. Am J Epidemiol 2012;175:228-35.
24. Jylhä M. What is self-rated health and why does it predict mortality? Towards a unified conceptual model. Soc Sci Med 2009;69:307-16.

25. Idler EL, Benyamini Y. Self-rated health and mortality: a review of twenty-seven community studies. J Health Soc Behav 1997;38:21-37.

26. Penninx BW, Leveille S, Ferrucci L, et al. Exploring the effect of depression on physical disability: longitudinal evidence from the established populations for epidemiologic studies of the elderly. Am J Public Health 1999;89:1346-52.

27. Bassuk SS, Berkman LF, Wypij D. Depressive symptomatology and incident cognitive decline in an elderly community sample. Arch Gen Psychiatry 1998;55:1073-81.

28. Braam AW, Prince MJ, Beekman ATF, et al. Physical health and depressive symptoms in older Europeans. Results from EURODEP. Br J Psychiatry 2005;187:35-42.

29. McDaid O, Hanly MJ, Richardson K, et al. The effect of multiple chronic conditions on self-rated health, disability and quality of life among the older populations of Northern Ireland and the Republic of Ireland: a comparison of two nationally representative cross-sectional surveys. BMJ Open 2013;3:e002571.

30. Ahmed T, Kone GK, Vafaei A, et al. Social support and social network scale, psychometric properties of a new scale for international use in older adults: the IMIAS Study [Abstract] 68th Annual Scientific Meeting of the Gerontological Society. 2015

31. Zunzunegui MV, Alvarado BE, Guerra R, et al. The mobility gap between older men and women: the embodiment of gender. Arch Gerontol Geriatr 2015;61:140-8.

32. Zunzunegui MV, Koné A, Johri M, et al. Social networks and self-rated health in two French-speaking Canadian community dwelling populations over 65. Soc Sci Med 2004;58:2069-81.

33. Pérez-Zepeda MU, Belanger E, Zunzunegui MV, et al. Assessing the validity of self-rated health with the Short Physical Performance Battery: a cross-sectional analysis of the International Mobility in Aging Study. PLOS ONE 2016;11:e0153855.

34. Zich JM, Attkisson CC, Greenfield TK. Screening for depression in primary care clinics-the CES-D and the BDI. Int J Psychiatry Med 1990;20:259-77.

35. Radloff LS. The CES-D Scale: a self-report depression scale for research in the general population. Appl Psycholo Meas 1977;1:385-401.

36. Morin AJS, Moullec G, Maïano C, et al. Psychometric properties of the Center for Epidemiologic Studies Depression Scale (CES-D) in French clinical and nonclinical adults. Rev Épidémiol Santé Publique 2011;59:327-40.

37. Ruiz-Grosso P, de Mola C, Vega-Dienstmaier JM, et al. Validation of the Spanish Center for Epidemiological Studies Depression and Zung Self-Rating Depression Scales: a comparative validation study. PLOS ONE 2012;7:e45413.

38. Batistoni SST, Neri AL, Cupertino APFB. Validity of the Center for Epidemiological Studies Depression Scale among Brazilian elderly. Rev Saude Publica 2007;41:598-605.

39. Thomas JL, Jones GN, Scarinci IC, et al. The utility of the CES-D as a depression screening measure among low-income women attending primary care clinics. The Center for Epidemiologic Studies-Depression. Int J Psychiatry Med 2001;31:25-40.

40. Bowling A. Just one question: if one question works, why ask several? J Epidemiol Community Health 2005;59:342-5.

41. de Boer AGEM, van Lanschot JJB, Stalmeier PFM, et al. Is a single-item visual analogue scale as valid, reliable and responsive as multi-item scales in measuring quality of life? Qual Life Res 2004:13:311-20.

42. Seeman TE. Social ties and health: the benefits of social integration. Ann Epidemiol 1996;6:442-51.

43. Mendes de Leon CF, Gold DT, Glass TA, et al. Disability as a function of social networks and support in elderly African Americans and Whites: the Duke EPESE 1986-1992. J Gerontol B Psychol Sci Soc Sci 2001;56:S179-90.

44. McNutt LA, Wu C, Xue X, et al. Estimating the relative risk in cohort studies and clinical trials of common outcomes. Am J Epidemiol 2003;157:940-3.

45. Barros AJ, Hirakata VN. Alternatives for logistic regression in cross-sectional studies: an empirical comparison of models that directly estimate the prevalence ratio. BMC Med Res Methodol 2003;3:21.

46. Sicotte M, Alvarado BE, León EM, et al. Social networks and depressive symptoms among elderly women and men in Havana, Cuba. Aging Ment Health 2008;12:193-201.

47. Huxhold $O$, Miche M, Schüz B. Benefits of having friends in older ages: differential effects of informal social activities on well-being in middle-aged and older adults. J Gerontol B Psychol Sci Soc Sci 2014;69:366-75. 
48. Vafaei A, Alvarado B, Zunzunegui MV, et al. Neighbourhood environment factors and the fall injuries in community-dwelling Canadian older adults: a validation study and exploration of structural confounding [Abstract]. 68th Annual Scientific Meeting of the Gerontological Society. 2015.

49. Beyene $Y$, Becker G, Mayen N. Perception of aging and sense of well-being among Latino elderly. J Cross Cult Gerontol 2002;17:155-72.

50. Cecchini S, Martínez R. Inclusive social protection in Latin America: a comprehensive, rights-based approach. SSRN J 2012. http://ssrn.com/abstract=2009321

51. Angel LE. Familia y vejez: realidad y perspectivas en Colombia. Segunda edición. Bogotá: Tercer Mundo, 1994.

52. Pelcastre-Villafuerte BE, Treviño-Siller S, González-Vázquez T, et al. [Social support and living conditions in poor elderly people in urban Mexico]. Cad Saude Publica 2011;27:460-70.

53. Ramos M, Wilmoth J. Social relationships and depressive symptoms among older adults in southern Brazil. J Gerontol B Psychol Sci Soc Sci 2003;58:S253-61.

54. Scharf T, Keating NC. From exclusion to inclusion in old age. Policy Press, 2012.
55. Hakulinen C, Pulkki-Råback L, Jokela M, et al. Structural and functional aspects of social support as predictors of mental and physical health trajectories: Whitehall II cohort study. J Epidemiol Community Health 2016;70:710-5.

56. Chi I. Cross-cultural gerontology research methods: challenges and solutions. Ageing Soc 2011;31:371-85.

57. Doulougou B, Gomez F, Alvarado B, et al. Factors associated with hypertension prevalence, awareness, treatment and control among participants in the International Mobility in Aging Study (IMIAS) J Hum Hypertens 2016;30:112-19.

58. Li A, Tu MT, Sousa AC, et al. Early life adversity and C-reactive protein in diverse populations of older adults: a cross-sectional analysis from the International Mobility in Aging Study (IMIAS). BMC Geriatr 2015;15:102.

59. Canadian Institute for Health Information. Health care in Canada 2011: a focus on seniors and aging. https://secure.cihi.ca/free products/HCIC_2011_seniors_report_en.pdf

60. Gomez F, Curcio CL, Duque G. Health care for older persons in Colombia: a country profile. J Am Geriatr Soc 2009;57:1692-6. http://doi.org/http://dx.doi.org/10.1111/j.1532-5415.2009.02341.x 